The Geneva Papers on Risk and Insurance, 21 (No. 80, July 1996) 303-307

\title{
Editors Introduction
}

\author{
by Howard Kunreuther, ${ }^{\text {Paul R. Kleindorfer * and Ortwin Renn }}{ }^{* *}$
}

This special issue of the Geneva Papers provides an overview and key papers from the international policy workshop, co-organized by the Wharton Risk Management and Decision Processes Center (Philadelphia, USA) and the Center of Technological Assessment (Stuttgart, Germany), held in conjunction with the European Society for Risk Analysis Conference in Stuttgart in May 1995.1 This was the second in a series of international workshops emphasizing risk, eco-efficiency and cooperation in the development of sustainable management strategies and related public policy initiatives. This workshop emphasized European perspectives on these issues, while the first Conference, held in Taipei in August 1994, emphasized Asian perspectives on the same issues. ${ }^{2}$

This special issue includes six papers that relate to the key themes that emerged from the Workshop. These themes focus on the role of insurance, regulations and standards in the management of health and environmental risks by industry and government. The papers also relate these themes to several proposed frameworks for integrating environmental and risk management with narrower economic objectives of private and public policy. This integration of economic, social and environmental objectives is in the spirit of calls for sustainable development which has become an increasingly important rallying point for environmentalists.

The Workshop developed the themes presented through a set of small group discussions in which the implications of these papers were explored in several policy and managerial contexts. A principal purpose of the small groups was to plan an agenda for evaluating alternative policy instruments, industry/government strategies and risk communication strategies for dealing with the challenges of sustainability and environmental risks. Each small group addressed this general question for a particular context. We provide a very brief summary of the key points raised in three of these contexts to illustrate the thinking of the Workshop and to stimulate the reader's interest in the papers which follow which were the catalyst for these discussions.

\footnotetext{
* Center for Risk Management and Decision Processes, The Wharton School, University of Pennsylvania, Philadelphia, PA.

** Center of Technology Assessment, in Buden Würdtenburg, Industriestr. 5, Stuttgart 10565, Germany.

${ }_{1}^{1}$ PolicyWorkshop on Management Strategies for Eco-Efficiency and Cooperation, May 24-25, 1995.

${ }^{2}$ Papers from the Taipei Conference appear in P. R. Kleindorfer, H. C. Kunreuther and D. S. Hong (eds) Energy, Environment and the Economy: Asian Perspectives (Cheltenham. UK: Edward Elgar), 1996 .
} 


\section{Risk management}

Several small groups focused on challenges in risk management in developing implementable and sustainable strategies for industry and government. The discussion focused on three interrelated elements: decision processes of stakeholders, regulation, and institutional arrangements promoting effective risk management.

On the decision process side, the key element addressed was how to expand the time frame and scope of decisionmaking to encompass broader temporal and environmental impacts of company decisions. The notion of moving from outcome/impact measurement alone to process determinants of good decisionmaking was underscored, with communication and dialog among all stakeholders. This is a key underlying fabric for evaluating and legitimating not only the quality of decisionmaking but also the longer-term values which should influence it.

On regulation, the idea of linking short-term costs to long-term benefits was discussed against the perspective of the traditional mode of environmental and risk regulation. This was contrasted with market-based mechanisms, including insurance and third-party compliance certification, as a means of promoting sustainable risk management. The tensions between these two regulatory approaches were highlighted, as well as their complementaries. Thus, standards (e.g., for cleanup) and definitions of environmental quality must be the purview of public agencies and the political process, but cost-effective implementation of these can very well be promoted by market-based mechanisms involving the insurance industry and various environmental and risk management service providers.

The institutional arrangements required for assuring proper incentives for company decision processes, regulation and viable private sector risk bearing entities are likely to be complex. Just a list of the stakeholders involved and their information needs is daunting. They include such diverse agent/organizations as: insurance and reinsurance companies, financial institutions, the public and its interest group surrogates, researchers and scientists, and regulators. In spite of this complexity, however, one perspective on how to move forward in crafting institutional arrangements is provided by focusing, for specific contexts (cleanup, water, air, etc.), on arrangements which assure the viability of a set of risk management strategies including insurance, incentives (taxes, subsidies and fines), standards, information provision, compensation and liability rules.

\section{Sustainability : regional perspectives}

A second major theme addressed by the small groups concerned sustainability. This included a range of issues surrounding company and regulatory processes, just as in the discussion of risk management. In addition, there was an active discussion of regional and interregional sustainability policies. This discussion focused on self-reliant and informed strategies for such key areas of regional sustainability as waste disposal, energy and overall consumption. Perhaps the most interesting element of this discussion at the Workshop was the emphasis on non-economic instruments, such as ethical norms, education and transparent public debate to promote a better understanding and a regionally coherent vision of what the public itself can and should do to assure sustainability. Sustainability was provided as an external challenge, based upon intergenerational equity, that would provide the regulatory framework under which to strive for market efficiency. 
On the issue of communication and public debate, the Workshop discussed a variety of means by which this might be accomplished. These included a more external role for the Center of Technology Assessment in promoting this debate, public involvement in environmental impact statements and evaluation procedures, feedback mechanisms on company and regional performance emphasizing the role of individual companies, sectors and households in relation to established sustainability goals for the region. The importance of developing "new heroes", (re-)establishing the credibility of politicans in the environmental area and institutionalizing the foundations of transparency and communication among stakeholders were underlined as key elements of regional and national sustainability.

\section{Eco-efficiency: in general and in the energy sector}

A final major theme in the small groups concerned eco-efficiency, which was differentiated from the parallel concept of sustainability as follows. "Sustainability" is a long-term, future-oriented, planet-wide and shared perspective concerning the necessary state of human capital, economic development, environment and technology which can credibly assure a quality of life and environment for all future generations, at least comparable to our own. "Eco-efficiency is defined on the basis of an agreed set of ecological and economic criteria, production and consumption technologies and valuation processes, which align products, market and technological developments with the longer-term objectives of sustainability. Thus, given these definitions, sustainability is a desired long-term objective, while ecoefficiency is a means to measuring and achieving progress toward sustainability.

The Workshop underlined here again the necessary institutional arrangements for assuring informed interaction among consumers, firms and regulatory agencies. The key point raised in this regard was to assure that myopia and narrow self-interest do not encourage companies to adopt low-quality technologies and imprudent environmental practices to save cost in the short-run at the expense of longer-term sustainability objectives. This issue was explored in detail in the more specific context of energy and fuel substitution for existing transportation systems. For this context it was agreed that the broad objectives of minimizing non-renewable energy, reducing pollution emissions and increasing mileage/unit (several "units" were discussed), while maintaining transportation affordability and mobility for society, were both desirable and understandable (to the public) eco-efficiency objectives. There are a host of barriers, however, to accomplishing these objectives, both on the supply side of the economy as well as on the demand side. On the supply side, issues of technology, transition cost and organizational inertia were underlined. On the demand side, the key was believed to be acceptance and legitimation to the public of the necessity to change from its current transportation modes to other, more eco-efficient alternatives. As with the other themes discussed, workshop participants saw the key to achieving these eco-efficiency objectives as first promoting a coherent public vision of the sustainability rationale for these objectives and second to link these objectives to incentives and understandable milestrones for the public and policy makers.

\section{Summary of papers}

As the above notes on the small group discussion highlight, a number of significant challenges face researchers, practitioners and policy makers in defining sustainable management and in designing a set of institutional arrangements which can work together to achieve 
implementable environmental and risk management solutions. The papers in this Special Issue address some of the problems posed in the small groups. They each offer a set of promising ideas for developing programs and policies for coping with the problems of sustainability and eco-efficiency that Europe faces in the coming years.

Gunnar Bengtsson's paper explores the possibility for sustainable development and the underlying value framework for sustainability. He examines these issues in the context of a value framwork suggested for priority setting in health care in Sweden. The principal features of this framework are an emphasis on human dignity, solidarity and cost-effectiveness. Bengtsson points out that one of the most important challenges for governments is to demonstrate that adherence to cost-effectiveness works in tandem with solidarity enhances the possibilities to maintain human dignity and sustainable development.

Jürg Spühler's paper discusses the Green Paper on Remedying Environmental Damage which has two key points: (1) the party damaging the environment rectifies the damage caused (the polluter pays principle) and (2) the collective compensation system takes care of those cases where no identifiable agent can be held responsible for environmental damage (the social principle). He pointed out that the key element to integrating these two principles in a manner which promotes effective risk management is the insurability of the resulting risks and the implied role for the insurance industry in risk management. Against this background, the paper explores the requirements for the legal framework to assure a proper role for risk management and the insurance industry and discusses these requirements in the context of the Green Paper.

Peter Zweifel's paper examines the impact that Environmental Impairment Liability (EIL) insurance has on five major policy instruments of environmental management - standards, taxes, tradable permits, tort law and capital markets. The paper's findings include the following. Standards specify maximum levels of environmental impairment and thus may help firms market insurance. However, the presence of insurance may (but need not) lower the stringency of standards. Insurance may detract from the effectiveness of internalized environmental taxes. Insurance encourages effectiveness of tradable permits by providing a hedge against price fluctuations and thus encouraging their trade. Experience rated insurance may enhance the effectiveness of tort law system. Insurance may increase the effectiveness of new financial instruments for dealing with catastrophic risks, such as the catastrophic futures options introduced on the Chicago Board of Trade.

Peter Hindle's paper, with Mssrs. De Smet, White and Owens, investigates four broad areas of environmental management concern : safety of processes and products; regulatory compliance; efficiency and effectiveness of resource use; and real and perceived needs of society. He describes Proctor and Gamble's (P\&G) framework and priorities for these areas of concern and focuses on a set of tools, including life-cycle analysis and internal measurement systems, to implement management's priorities. The $P \& G$ framework, in its scope and detail, is a persuasive argument that sustainable management is not only compatible with the traditional economic mission of the firm. Properly integrated with business strategy, sustainable management can be a fundamental driver of business profitability.

Dirk Matten's paper addresses the problems of environmental risk management from the perspective of a private company. Matten argues that the tasks of risk management go beyond conventional methods of optimizing outcomes on the basis of probability calculations. Management of environmental risk requires in his view a relationship with all relevant social groups and institutions that play a part in the management process. Based on the 
framework of institutional economics, Matten designs a risk management programme that integrates organizational, communicative, controlling, and auditing tools as a means of improving safety culture, to develop in-house human resources and to interact with the outside world. These management tools serve as strategies for signaling potential hazards and developing a positive image in the business world as well as in the public at large.

Ulrich Müller-Herold's paper introduces a conceptual alternative to risk analysis as the basis of risk management. Risk denotes the combination of probability times magnitude of adverse effects. Conventional management strategies are designed to reduce either one of the two components. Müller-Herold argues that the precautionary principle in environmental policy making requires an approach that implies management steps at an earlier stage. His target is what he calls "endangerment". Controlling endangerment means controlling the scope and range of the potential for damage. He develops a taxonomy of endangerment that comprises two main factors: spatial extension and persistence over time. These two factors determine the degree of endangerment regardless of their strength of destructive potential. So far the term "endangerment" lacks a well-defined quantitative meaning. Müller-Herold develops a quantitative approach and illustrates this with an example. 